\title{
Weighted gene coexpression correlation network analysis reveals a potential molecular regulatory mechanism of anthocyanin accumulation under different storage temperatures in 'Friar' plum
}

Xueling $\mathrm{Li}^{1,2,3+}$, Yudou Cheng ${ }^{2,3+}$, Meng Wang ${ }^{4}$, Sujuan Cui ${ }^{1}$ and Junfeng Guan ${ }^{2,3^{*}}$

\begin{abstract}
Background: Flesh is prone to accumulate more anthocyanin in postharvest'Friar' plum (Prunus salicina Lindl.) fruit stored at an intermediate temperature. However, little is known about the molecular mechanism of anthocyanin accumulation regulated by storage temperature in postharvest plum fruit.

Results: To reveal the potential molecular regulation mechanism of anthocyanin accumulation in postharvest 'Friar' plum fruit stored at different temperatures $\left(0^{\circ} \mathrm{C}, 10^{\circ} \mathrm{C}\right.$ and $\left.25^{\circ} \mathrm{C}\right)$, the fruit quality, metabolite profile and transcriptome of its flesh were investigated. Compared to the plum fruit stored at $0{ }^{\circ} \mathrm{C}$ and $25^{\circ} \mathrm{C}$, the fruit stored at $10^{\circ} \mathrm{C}$ showed lower fruit firmness after 14 days and reduced the soluble solids content after 21 days of storage. The metabolite analysis indicated that the fruit stored $a t 10^{\circ} \mathrm{C}$ had higher contents of anthocyanins (pelargonidin-3-Oglucoside, cyanidin-3-O-glucoside, cyanidin-3-O-rutinoside and quercetin-3-O-rutinose), quercetin and sucrose in the flesh. According to the results of weighted gene coexpression correlation network analysis (WGCNA), the turquoise module was positively correlated with the content of anthocyanin components, and flavanone 3-hydroxylase (F3H) and chalcone synthase (CHS) were considered hub genes. Moreover, MYB family transcription factor APL (APL), MYB10 transcription factor (MYB10), ethylene-responsive transcription factor WIN1 (WIN1), basic leucine zipper 43-like (bZIP43) and transcription factor bHLH111-like isoform X2 (bHLH111) were closely related to these hub genes. Further qRT-PCR analysis verified that these transcription factors were specifically more highly expressed in plum flesh stored at $10^{\circ} \mathrm{C}$, and their expression profiles were significantly positively correlated with the structural genes of anthocyanin synthesis as well as the content of anthocyanin components. In addition, the sucrose biosynthesis-associated gene sucrose synthase (SS) was upregulated at $10^{\circ} \mathrm{C}$, which was also closely related to the anthocyanin content of plum fruit stored at $10^{\circ} \mathrm{C}$.
\end{abstract}

Conclusions: The present results suggest that the transcription factors APL, MYB10, WIN1, bZIP43 and bHLH111 may participate in the accumulation of anthocyanin in 'Friar' plum flesh during intermediate storage temperatures

*Correspondence: junfeng-guan@263.net

${ }^{\dagger}$ Xueling Li and Yudou Cheng are co-first authors.

${ }^{3}$ Plant Genetic Engineering Center of Hebei Province, Shijiazhuang, Hebei

Province 050051, People's Republic of China

Full list of author information is available at the end of the article

(c) The Author(s) 2021. Open Access This article is licensed under a Creative Commons Attribution 4.0 International License, which permits use, sharing, adaptation, distribution and reproduction in any medium or format, as long as you give appropriate credit to the original author(s) and the source, provide a link to the Creative Commons licence, and indicate if changes were made. The images or other third party material in this article are included in the article's Creative Commons licence, unless indicated otherwise in a credit line to the material. If material is not included in the article's Creative Commons licence and your intended use is not permitted by statutory regulation or exceeds the permitted use, you will need to obtain permission directly from the copyright holder. To view a copy of this licence, visit http://creativecommons.org/licenses/by/4.0/. The Creative Commons Public Domain Dedication waiver (http://creativeco mmons.org/publicdomain/zero/1.0/) applies to the data made available in this article, unless otherwise stated in a credit line to the data. 
by regulating the expression of anthocyanin biosynthetic structural genes. In addition, the SS gene may play a role in anthocyanin accumulation in plum flesh by regulating sucrose biosynthesis.

Keywords: Plum, WGCNA, Transcriptome, Anthocyanin, Storage

\section{Background}

Anthocyanin is a kind of water-soluble flavonoid that is derived from the branch of flavonoids, and it gives flowers and fruits various and graceful colours [1,2]. As an antioxidant, anthocyanin can effectively remove free radicals such as reactive oxygen species (ROS) when plants suffer environmental stress, protecting plants from damage [3]. In addition, it has been shown that anthocyanin intake is beneficial to human prevention of cardiovascular diseases and cancer [4]; thus, anthocyanin has been widely studied recently.

The biosynthetic pathway of anthocyanins in higher plants is conserved, and anthocyanins are synthesized from phenylalanine catalysed by a series of enzymes. The enzyme-associated genes involved in anthocyanin synthesis are divided into early biosynthesis genes (EBGs) and late biosynthesis genes (LBGs) [5]. EBGs include chalcone synthase (CHS), chalcone isomerase (CHI), flavanone 3-hydroxylase (F3H) and flavonoid-3'hydroxylase $\left(\mathrm{F} 3^{\prime} \mathrm{H}\right)$, and they are common to different flavonoid synthesis branches [6, 7]. LBGs mainly include dihydroflavonol 4-reductase (DFR), leucoanthocyanidin dioxygenase/anthocyanin synthetase (LDOX/ANS) and UDP-glucose: flavonoid 3-O-glucosyltransferase (UFGT), and they contribute to the production of various anthocyanin components by catalysing flavanonol and its subsequent derivatives [8]. Anthocyanin biosynthesisrelated genes are regulated by many transcription factors, among which MYB-bHLH-WD40 (MBW) has been widely studied. The MBW complex positively regulates the expression of structural genes by binding to cis-acting elements on the promoter regions of genes (such as $D F R$, $L D O X / A N S, U F G T$, etc.) and then facilitates the accumulation of anthocyanin in plants [7, 9-12]. In addition, transcription factors such as COP1 (CONSTITUTIVE PHOTOMORPHOGENIC 1), JAZ (JASMONATE ZIMDOMAIN), NAC (NAM, ATAF1/2, CUC2), SPL (SQUAMOSA promoter-binding protein-like) and WRKY have been considered to regulate anthocyanin biosynthesis by interacting with the MBW complex [13-18].

Anthocyanin accumulation can be affected by light, temperature, hormones and mineral nutrition, and favourable low-temperature conditions are one of the important factors that induce the biosynthesis of anthocyanins [16, 19-24]. In grape fruit, cold treatment $\left(4^{\circ} \mathrm{C}\right)$ enhanced the expression levels of $V v F 3 H, V v P A L$,
$V v C H S 3, V v C H S 2$ and $V v L D O X$ in the peel and subsequently led to anthocyanin accumulation [25]. Blood orange stored at $4^{\circ} \mathrm{C}$ exhibited 3 times higher anthocyanin content in the flesh than that stored at $25^{\circ} \mathrm{C}$ [20]. Compared with the $27^{\circ} \mathrm{C}$ treatment, the apple fruit under a lower temperature $\left(17^{\circ} \mathrm{C}\right)$ showed a higher anthocyanin content and reddened quickly. Further study showed that the transcription factor MdbHLH3 played a crucial role by interacting with $M d M Y B 1$ to upregulate the expression of MdDFR and MdUFGT by binding their promotor regions [23]. In peach, the anthocyanin content in the flesh increased significantly when the fruit was stored at $16^{\circ} \mathrm{C}$, while the transcript levels of anthocyanin biosynthesis-associated genes were enhanced [26]. The flesh of 'Friar' plum fruit is prone to reddening when it is stored at $5-15^{\circ} \mathrm{C}$, and it was found that the main anthocyanin component is cyanidin-3-O-glucoside [27, 28]. However, the molecular regulation mechanism of the intermediate temperature causing flesh reddening in 'Friar' plum fruit is less well known. In the present study, flesh colouration in postharvest 'Friar' plum fruit stored at different temperatures $\left(0^{\circ} \mathrm{C}, 10^{\circ} \mathrm{C}\right.$ and $\left.25^{\circ} \mathrm{C}\right)$ was observed, and subsequently, metabolite profile and comparative transcriptome analysis in the flesh was performed. By constructing a coexpression network through WGCNA, hub genes and candidate regulatory transcription factors were identified. These findings provide new insights into the mechanism of intermediate temperature-induced anthocyanin accumulation in postharvest plum fruit.

\section{Results}

Effect of different storage temperatures on the fruit quality of 'Friar' plum

Within 28 days of storage, there were no obvious colour changes in the flesh of fruit stored at $0{ }^{\circ} \mathrm{C}$ and $25^{\circ} \mathrm{C}$, while the flesh of fruit stored at $10^{\circ} \mathrm{C}$ turned red on the 14th day of storage (Fig. 1a). Among the three different storage temperatures, the firmness of the fruit stored at $10^{\circ} \mathrm{C}$ decreased the fastest, while the fruit stored at $0^{\circ} \mathrm{C}$ decreased the slowest (Fig. 1b). After 21 days of storage, the soluble solids content (SSC) in the fruit stored at $10^{\circ} \mathrm{C}$ appeared significantly lower than that in the fruit stored at $0^{\circ} \mathrm{C}$ and $25^{\circ} \mathrm{C}$ (Fig. 1c). 


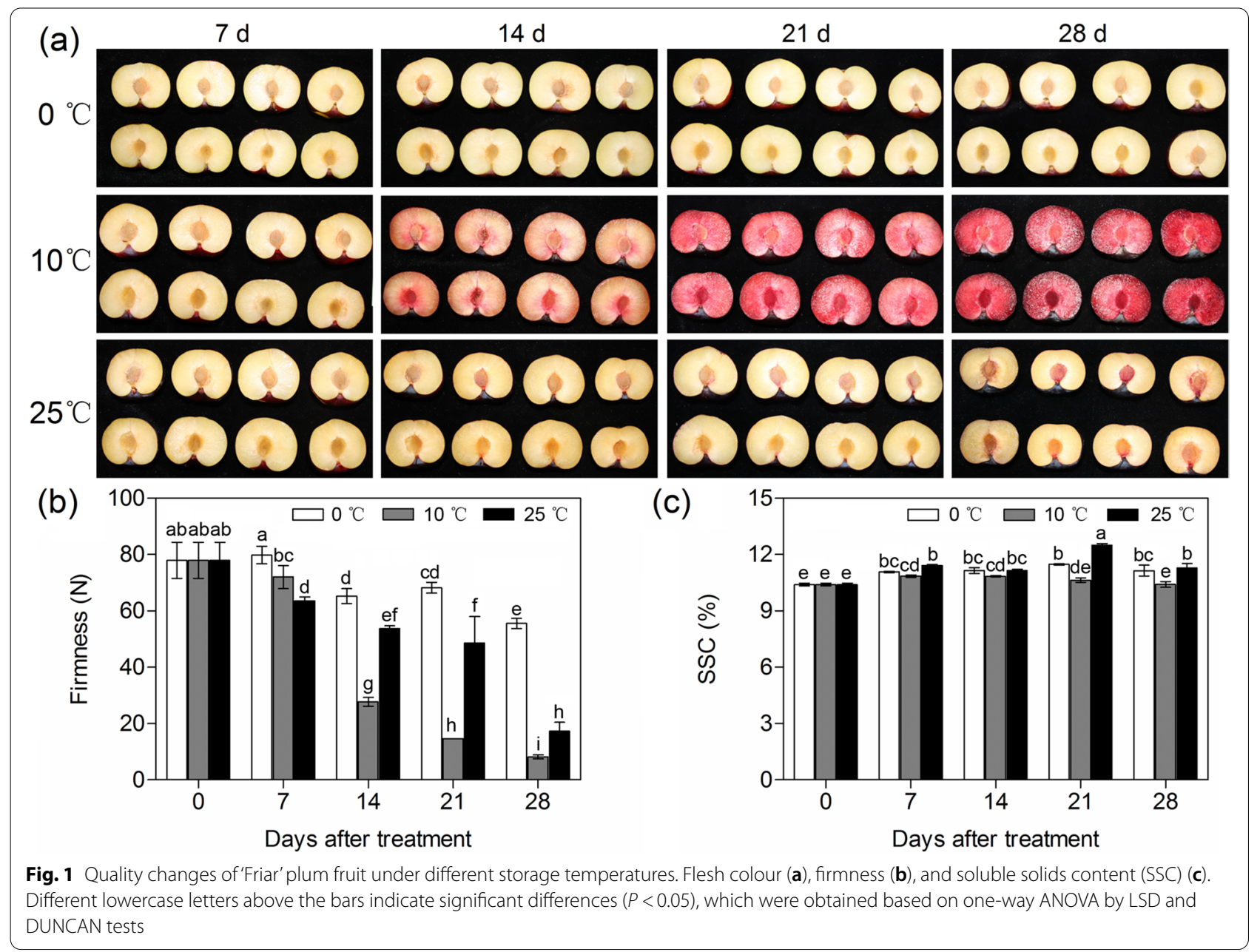

Identification of the anthocyanin and phenolic metabolite profile related to flesh reddening

The UPLC-MS/MS results showed that the anthocyanins in the flesh of 'Friar' plum fruit mainly contained pelargonidin 3-O-glucoside, cyanidin-3-O-glucoside, cyanidin-3-O-rutinoside, and quercetin-3-O-rutinose, and their contents were much higher in fruit stored at $10^{\circ} \mathrm{C}$ after 21 days than in those stored at $0{ }^{\circ} \mathrm{C}$ and $25^{\circ} \mathrm{C}$ (Fig. 2a-d). Moreover, the contents of cyanidin-3-Oglucoside and cyanidin-3-O-rutinoside were much higher than pelargonidin 3-O-glucoside and quercetin3-O-rutinose, indicating that cyanidin-3-O-glucoside and cyanidin-3-O-rutinoside were the main ingredients contributing to flesh reddening in 'Friar' plum fruit. In this work, polyphenolic components were also studied. Only the quercetin content in the flesh of fruit stored at $10^{\circ} \mathrm{C}$ accumulated markedly, and the other polyphenolic components, such as neochlorogenic acid, chlorogenic acid, epicatechin, catechin hydrate, and quinic acid, were ubiquitous and less changed among all storage conditions (Fig. 2e-j), suggesting that quercetin was also related to the process of flesh reddening in 'Friar' plum fruit.

\section{Transcriptome analysis}

To explore the regulatory mechanism of anthocyanin accumulation in the flesh of 'Friar' plum fruit, the samples at five detection time points $(0,7,14,21,28 \mathrm{~d})$ from the three different storage temperatures were used for deep RNA-seq analysis. After sequencing quality control, a total of $307.14 \mathrm{~Gb}$ of clean data were obtained, and the Q30 base percentage of each sample was not less than $91.47 \%$. Then, the clean data were mapped to the European plum reference genome, with the mapping ratio varying from 84.98 to $93.00 \%$. A total of 129,821 annotated genes were obtained. Differentially expressed genes (DEGs) were identified based on their expression levels in different samples, and functional annotation and enrichment analysis were performed. A total of 40,417 genes were differentially expressed under storage temperatures of $10^{\circ} \mathrm{C}, 25^{\circ} \mathrm{C}$, and $0^{\circ} \mathrm{C}$ (Fig. 3a). To screen the candidate genes related to anthocyanin biosynthesis, our study 

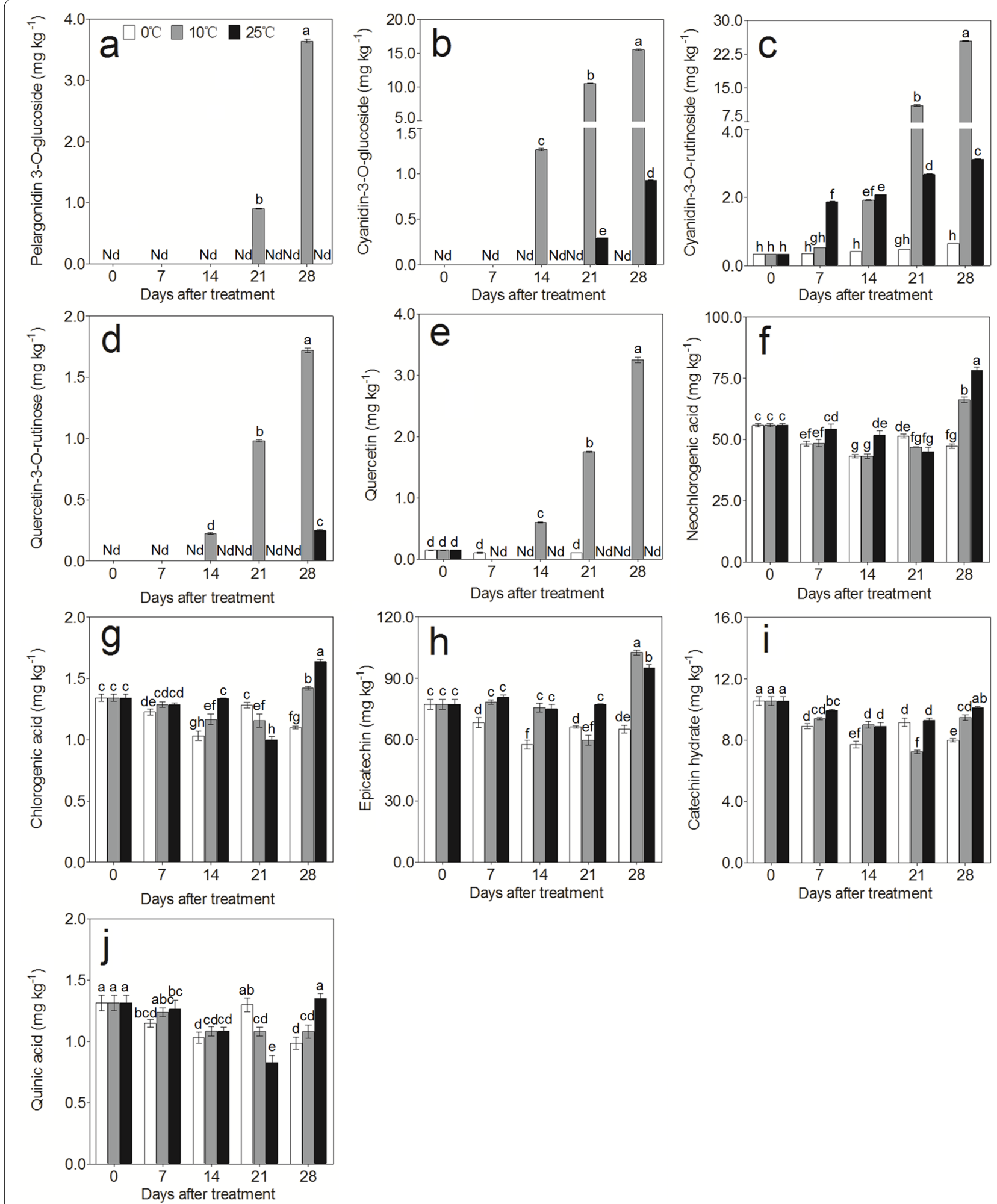

Fig. 2 Changes in anthocyanin and polyphenolic components in 'Friar' plum flesh under different storage temperatures. a Pelargonidin-3-O-glucoside, b Cyanidin-3-O-glucoside, c cyanidin-3-O-rutinoside, d Quercetin-3-O-rutinose, e Quercetin, $\mathbf{f}$ Neochlorogenic acid, $\mathbf{g}$ Chlorogenic acid, $\mathbf{h}$ Epicatechin, $\mathbf{i}$ Catechin acid, and $\mathbf{j}$ Quinic acid. Different lowercase letters above the bars indicate significant differences $(P<0.05)$, which were obtained based on one-way ANOVA by LSD and DUNCAN tests. Nd stands for non-detectable 

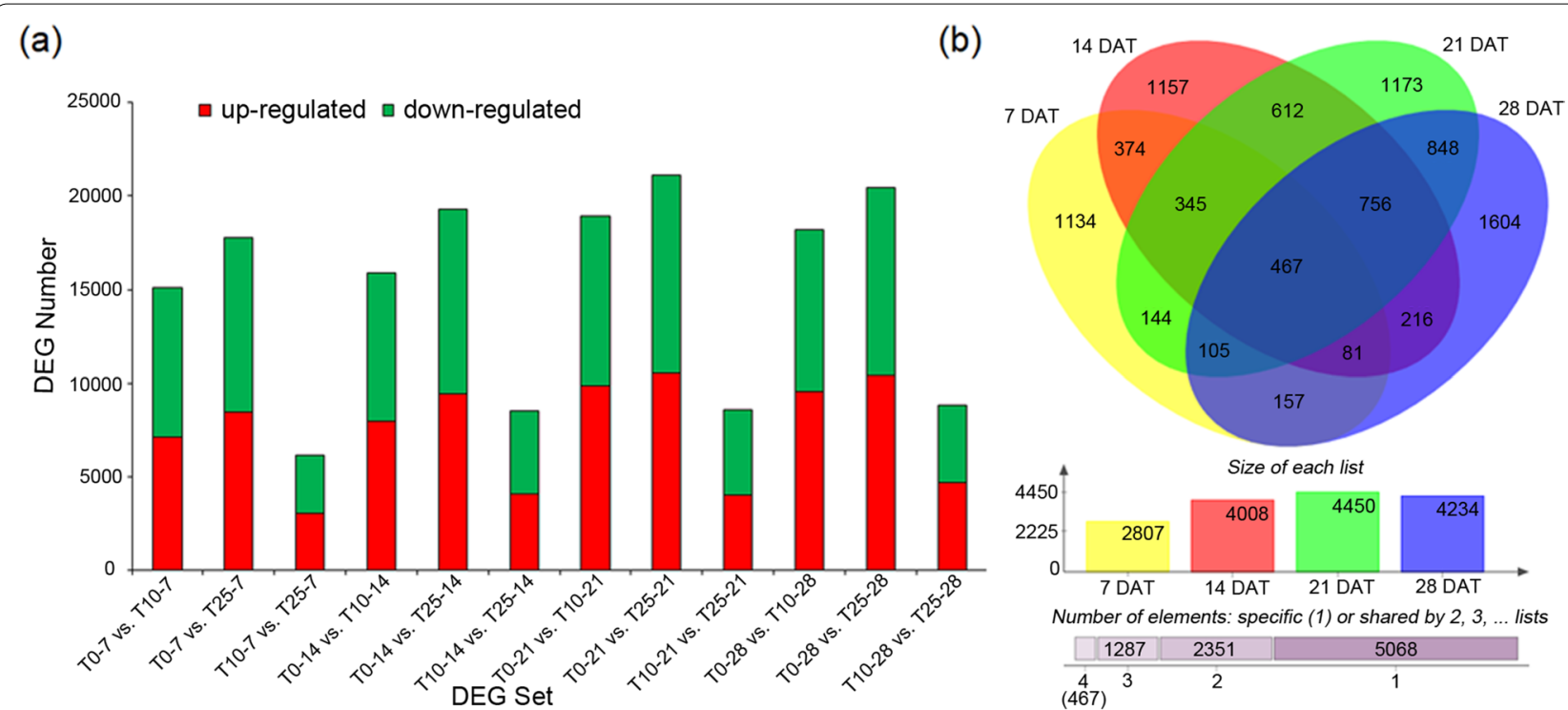

Fig. 3 Summary of differentially expressed genes under different storage temperatures in 'Friar' plum. a Number of DEGs in different DEG sets. T0-7 vs. T10-7 represents the DEG set in which samples stored at $0^{\circ} \mathrm{C}$ for 7 days versus samples stored at $10^{\circ} \mathrm{C}$ for 7 days. $\mathbf{b}$ Venn diagram shows DEGs in both $10^{\circ} \mathrm{C}$ vs. $0^{\circ} \mathrm{C}$ and $10^{\circ} \mathrm{C}$ vs. $25^{\circ} \mathrm{C}$ at different storage time points. DAT represents days after treatment

mainly focused on the DEGs at $10^{\circ} \mathrm{C}$ vs. $0^{\circ} \mathrm{C}$ and $10^{\circ} \mathrm{C}$ vs. $25^{\circ} \mathrm{C}$. There were $2807,4008,4450$, and 4234 genes that were differentially expressed on Days $7,14,21$, and 28, respectively, at $10^{\circ} \mathrm{C}$ vs. $0^{\circ} \mathrm{C}$ and $10^{\circ} \mathrm{C}$ vs. $25^{\circ} \mathrm{C}$ (Fig. 3b). Among them, 467 genes were consistently differentially expressed (Fig. 3b).

\section{Construction of a WGCNA and coexpression network}

To obtain hub genes related to anthocyanin accumulation, the relationships of DEGs, anthocyanin components and storage temperature for each sample were analysed by constructing a WGCNA (Fig. 4). Sample clustering showed that the three biological replicates of each treatment were very good (Fig. 4a). Ten coexpression modules were identified by WGCNA (Fig. 4b), among which the turquoise module was positively correlated with the contents of pelargonidin-3-O-glucoside $(\mathrm{r}=0.67, p$ value $=3 \mathrm{e}-06)$, cyanidin-3-O-glucoside $(\mathrm{r}=0.80, \quad p \quad$ value $=8 \mathrm{e}-11), \quad$ cyanidin-3-O-rutinoside $(\mathrm{r}=0.75, p$ value $=4 \mathrm{e}-08)$, and quercetin-3-O-rutinose $(\mathrm{r}=0.83, p$ value $=6 \mathrm{e}-11)$. In addition, the turquoise module was positively correlated with the storage temperature of $10^{\circ} \mathrm{C}$, and the correlation coefficient was 0.90 ( $p$ value $=6 \mathrm{e}-15$ ) (Fig. 4c). According to GO and KEGG enrichment of the candidate genes in the turquoise module (1416 genes in total), 33 genes were mapped to the flavonoid metabolism pathway, and 31 genes were mapped to the starch and sugar metabolism pathway (see Additional file 1: Figs. S1 and S2).

\section{Identification of candidate genes involved in anthocyanin biosynthesis}

A total of 43 structural genes involved in anthocyanin biosynthesis were obtained in the turquoise module, and a heatmap of their expression profiles in the flesh of 'Friar' plum fruit was drawn based on their FPKM value $(\log 10($ FPKM+1)) (Fig. 5). The 43 structural genes from all major steps of the anthocyanin biosynthesis pathway were distributed as follows: four phenylalanine ammonia-lyase genes $(P A L)$, one 4-coumarate: coenzyme A ligase $(4 C L)$, fourteen chalcone synthase genes $(\mathrm{CHS})$, four chalcone isomerase genes (CHI), one flavonoid-3'hydroxylase gene $(F 3 ' H)$, four flavanone 3-hydroxylase genes $(F 3 H)$, three dihydroflavonol 4-reductase genes $(D F R)$, five leucoanthocyanidin dioxygenase/anthocyanin synthase genes (LDOX/ANS) and seven UDP-glucose: flavonoid 3-O-glucosyltransferase genes (UFGT).

Furthermore, the expression patterns of eight representative structural genes involved in anthocyanin biosynthesis, PsPAL (Pd.00g835470), PsCHS (Pd.00g300780), PsCHI (Pd.00g402750), PsF3H (Pd.00g891590), PsF3'H (Pd.00g637710), PsDFR (Pd.00g1089860), PsLDOX (Pd.00g746630) and PsUFGT (Pd.00g247850), were studied via qRT-PCR, and the transcripts of these genes were significantly higher in the flesh of plum fruit stored at $10^{\circ} \mathrm{C}$ than in that stored at $0{ }^{\circ} \mathrm{C}$ and $25^{\circ} \mathrm{C}$ (Fig. $5 \mathrm{c}$ ), which was consistent with the results of transcriptome analysis based on the correlation analysis (Fig. 5d). 


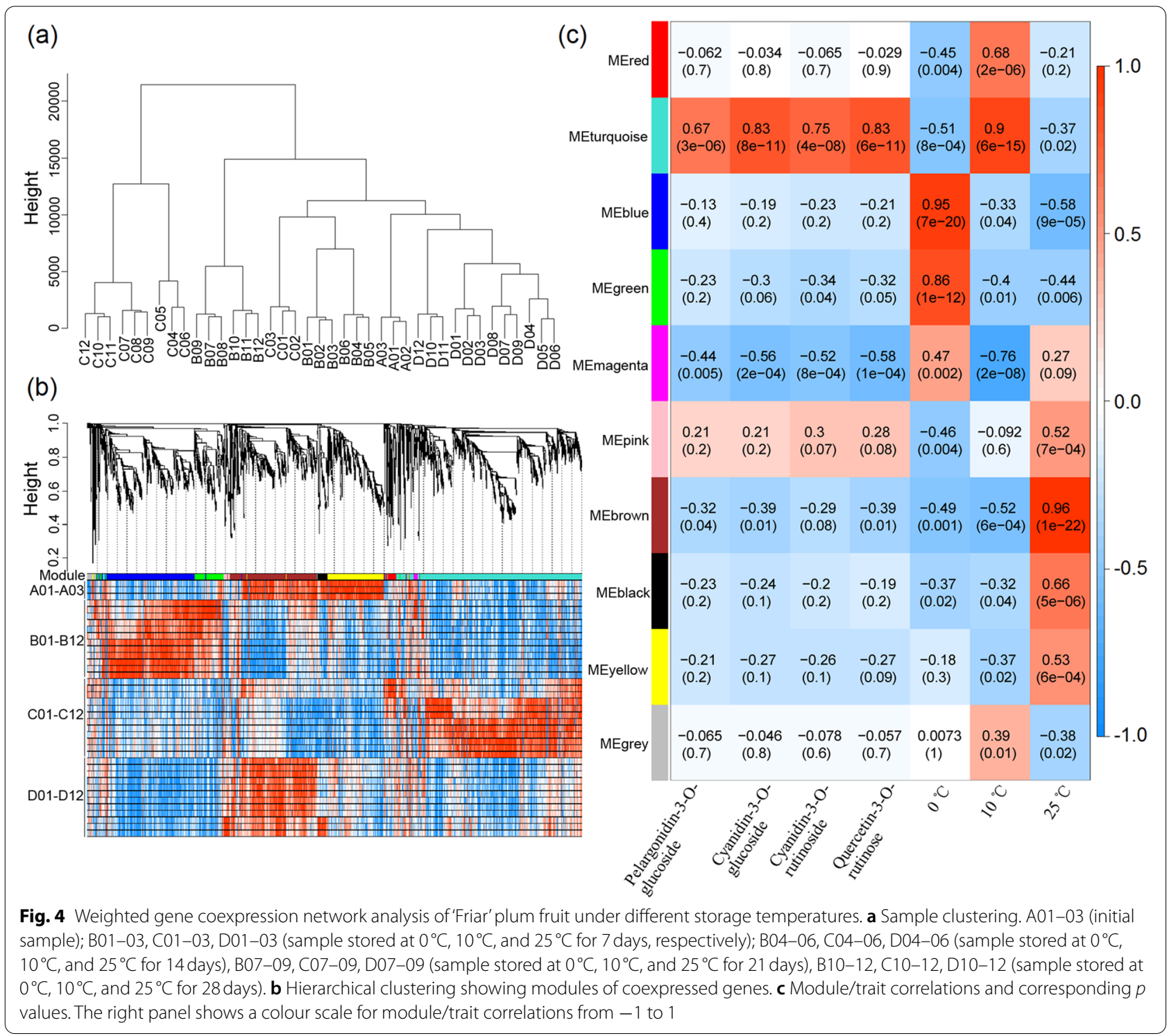

\section{Identification of genes involved in carbohydrate metabolism}

Carbohydrates are considered substrates for anthocyanin synthesis, and the change in soluble sugar content was detected by HPLC. The contents of glucose, fructose and sorbitol showed downward trends at three different storage temperatures. The sucrose content decreased in the flesh of plum fruit during $0^{\circ} \mathrm{C}$ storage but increased during $10^{\circ} \mathrm{C}$ and $25^{\circ} \mathrm{C}$ storage; moreover, it was higher at $0^{\circ} \mathrm{C}$ than at $25^{\circ} \mathrm{C}$ (Fig. 6a). In the turquoise module, which was related to anthocyanin synthesis, five genes were involved in starch and sugar metabolism, including two hexokinases (HXKs) and three sucrose synthases (SSs) (Fig. 6b). Correlation analysis showed that the expression patterns of the SS genes were positively correlated with sucrose content and anthocyanin content

Fig. 5 Analysis of genes related to anthocyanin biosynthesis in the turquoise module. a Anthocyanin biosynthetic pathway. The bold font indicates the genes obtained in the turquoise module and the anthocyanin components detected in the flesh of 'Friar' plum fruit. $\mathbf{b}$ Heatmap of the expression levels of differentially expressed genes (DEGs) involved in anthocyanin biosynthesis. c qRT-PCR detection of anthocyanin synthesis-related structural genes, PSPAL (Pd.00 g835470), PsCHS (Pd.00 g300780), PsCHI (Pd.00 g402750), PsF3H (Pd.00 g891590), PsF3'H (Pd.00 g637710), PsDFR (Pd.00 g 1089860), PsLDOX (Pd.00 g746630), and PsUFGT (Pd.00 g247850). d Correlation analysis of the expression profiles in qRT-PCR (qPCR) and transcriptome data (RNA-seq) $(N=13,|r|>0.55$ represents a significant correlation between the two sets of data) 
(a)
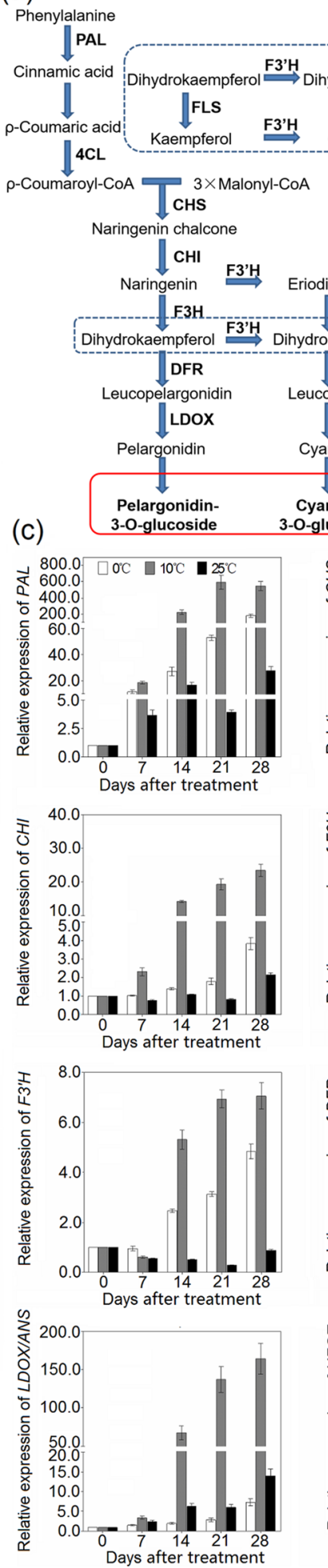

$\Longrightarrow$ Dihydromyricetin $\sqrt{ }$ FLS $\$ FLS Quercetin $\Longrightarrow$ Myricetin (1) (1)

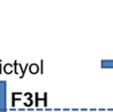
Dinydrotricetin oquercetin $\Longrightarrow$ Dihydromyricetin DFR Leucodelphinidin LDOX LDOX

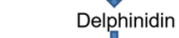
Anthocyanins Delphinidin-glucoside 3-O-glucoside

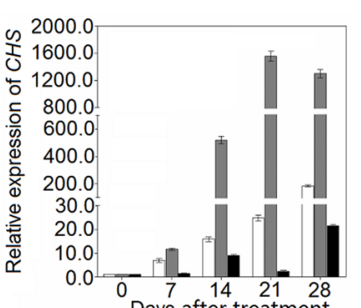

Days after treatment
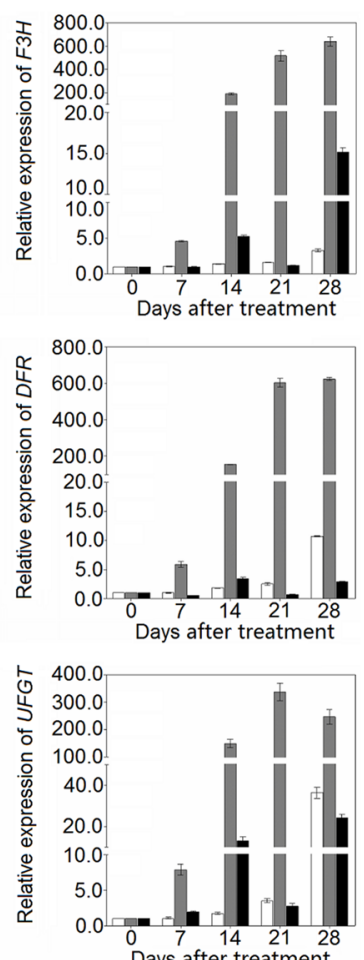

Days after treatment (b)
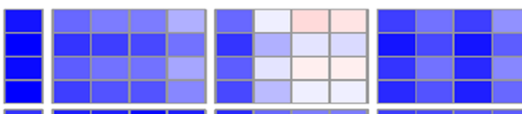

d.00g835470 Pd.00g501070 Pd.00g465560 Pd.00g027940

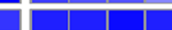
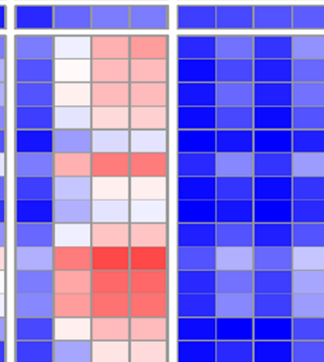

d. 009974060 | $4 C L$
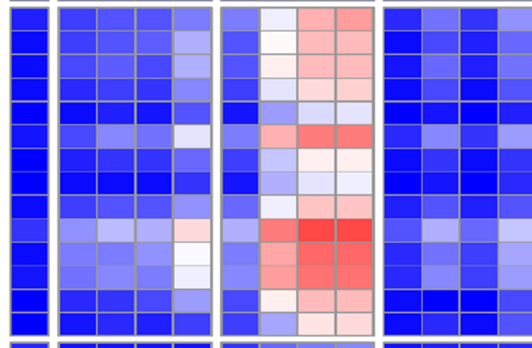

Pd 00g113960

Pd.00g276470

d.00g113970

Pd.00g300760

Pd.00g276450

Pd.00g113980

Pd.00g276460

Pd.00g210340

Pd.00g210350

Pd.00g300780

Pd.00g061390

Pd.00g210360

Pd.00g061380

Pd.00g061370

Pd.00g606930 Pd.00g943260 Pd.00g402750 Pd.00g911730

Pd.00g637710 | F3'H

Pd.00g637710 Pd.00g891590 $\mathrm{Pd}$ 00g617550 $\mathrm{F3H}$
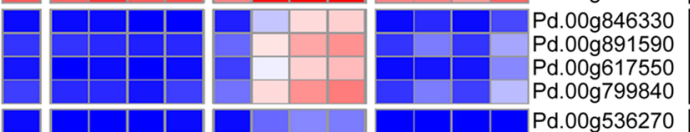

Pd.00g536270 |FLS
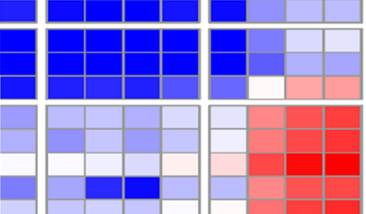

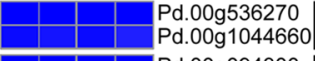
\begin{tabular}{l|l} 
Pd.00g094300 & \\
Pd.00g599600 & DFR
\end{tabular}

Pd.00g1089860

Pd.00g1223410

Pd.00g565630

Pd.00g746630 Pd.00g951800 Pd.00g411940

LDOXIANS
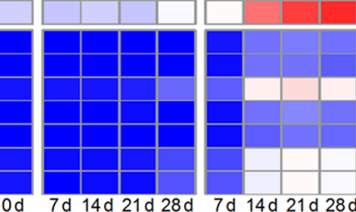
\begin{tabular}{|l|l|l|}
\hline & & Pd.00g177050 \\
\hline & & Pd.00g1257180 \\
& Pd.00g247850 \\
\hline & & Pd.00g625360 \\
\hline & & Pd.00g641610
\end{tabular} \begin{tabular}{|l|l|l|}
\hline & & Pd.00g177050 \\
\hline & & Pd.00g1257180 \\
& Pd.00g247850 \\
\hline & & Pd O0g625360 \\
\hline & & Pd.00g641610
\end{tabular} \begin{tabular}{|l|l|l|}
\hline & & Pd.00g177050 \\
\hline & & Pd.00g1257180 \\
& Pd.00g247850 \\
\hline & & Pd.00g625360 \\
\hline & & Pd.00g641610
\end{tabular}

\begin{tabular}{l|l} 
d.00g625360 & UFGT
\end{tabular} Pd.00g103610
Pd.00g974180

(d)

\section{PsPAL(qPCR)} PsCHS(qPCR)

PSCHI(qPCR) $0.940 .94 \quad 1$

PsF3'H(qPCR) $0.810 .810 .79 \quad 1$

PsF3H(qPCR) $0.860 .860 .880 .53 \quad 1$

PSDFR(qPCR) $0.890 .890 .97 \quad 0.7 \quad 0.92 \quad 1$

PsLDOX(qPCR) $0.80 .80 .790 .460 .920 .82 \quad$ I

PSUFGT(qPCR) $0.870 .870 .860 .540 .930 .890 .97 \quad 1$

PsPAL(seq) $0.980 .980 .920 .790 .880 .880 .820 .88 \quad 1$

PsCHS(seq) $0.940 .940 .920 .70 .910 .910 .850 .890 .96 \quad 1$

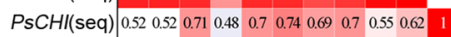

PsF3'H(seq) 0.820 .820 .810 .970 .590 .730 .480 .550 .810 .760 .49

$\begin{array}{lllllllll}\text { PsF3H(seq) } & 0.4 & 0.4 & 0.530 .260 .720 .6 & 0.68 & 0.620 .440 .54 & 0.86 & 0.33 & \text { I }\end{array}$

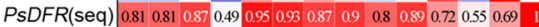

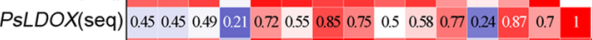

PsUFGT(seq) $0.760 .760 .760 .40 .930 .810 .980 .970 .80 .840 .740 .430 .740 .890 .87 \quad 1 \quad 0.0$

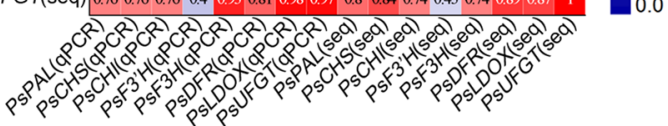

Fig. 5 (See legend on previous page.) 

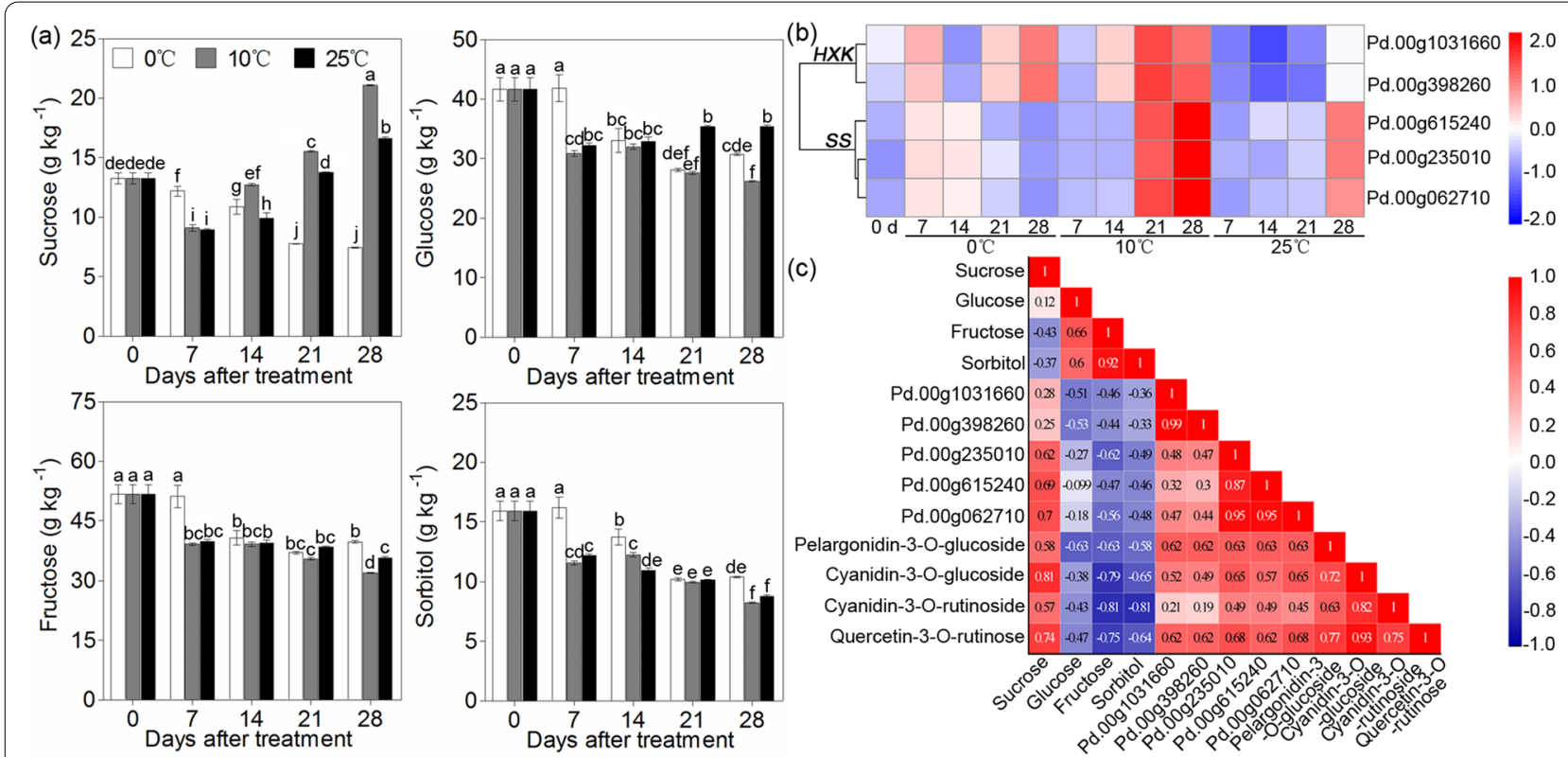

Fig. 6 Soluble sugar content and expression pattern of carbohydrate metabolism-related genes under different storage temperatures. a Glucose, fructose, sorbitol and sucrose contents in 'Friar' plum fruit under different storage temperatures. $\mathbf{b}$ Heatmap of the expression levels of carbohydrate metabolism-related genes in the turquoise module. c Correlation analysis of anthocyanin content, soluble sugar content and expression profiles of carbohydrate metabolism-related genes ( $N=13,|r|>0.55$ represents a significant correlation between the two sets of data). Different lowercase letters above the bars indicate significant differences $(P<0.05)$, which were obtained based on one-way ANOVA by LSD and DUNCAN tests

(Fig. 6c), suggesting that higher expression levels of these genes were beneficial to carbohydrate metabolism, which contributed to anthocyanin accumulation in the flesh under storage at $10^{\circ} \mathrm{C}$.

\section{Screening potential transcription factors that regulate anthocyanin synthesis}

To further explore the molecular regulatory mechanism of anthocyanin biosynthesis in the flesh of 'Friar' plum fruit, a coexpression network was constructed based on the genes present in the turquoise module. In the network, three F3H genes (Pd.00 g799840, Pd.00 g891590 and Pd.00 g617550) and two CHS genes (Pd.00 g276460 and Pd.00g113960) were identified as hub genes (Fig. 7a), and five transcription factor genes, MYB10, $A P L, W I N 1, b H L H 111$ and $b Z I P 43$, were found to be coexpressed with anthocyanin biosynthesis-related genes. Among the five transcription factor genes, MYB10 and WIN1 were closely related to CHS, F3H, $D F R$ and $L D O X, A P L$ was closely related to $C H S, F 3 H$ and DFR, bHLH111 was only closely related to $F 3 H$, and bZIP43 was closely related to CHS and F3H. In addition, there was a positive correlation between $A P L$ and WIN1 (Fig. 7b).

The heatmap based on the transcriptome data showed that the expression levels of APL, WIN1, MYB10, bHLH111 and bZIP43 were obviously upregulated in the fruit stored at $10^{\circ} \mathrm{C}$, while there was little change in the fruit stored at $0^{\circ} \mathrm{C}$ and $25^{\circ} \mathrm{C}$ (Fig. 7c). Meanwhile, the qRT-PCR results indicated that the transcripts of these five detected genes in the fruit stored at $10^{\circ} \mathrm{C}$ were markedly higher than those in the fruit stored at $0^{\circ} \mathrm{C}$ and $25^{\circ} \mathrm{C}$ (Fig. 7d), which was consistent with the transcriptome analysis results based on the correlation analysis (Fig. 7e). Furthermore, the expression patterns of the five transcription factor genes were positively correlated with the changes in the expression levels of the structural genes and the anthocyanin content (see Additional file 1: Fig. S3). It was proposed that APL, WIN1, MYB10, bHLH111 and $b Z I P 43$ might be involved in anthocyanin accumulation by regulating the expression of structural genes associated with anthocyanin biosynthesis.

\section{Discussion}

\section{Intermediate temperature is beneficial to promote} anthocyanin accumulation in plum fruit

Temperature is an important environmental factor that affects anthocyanin accumulation. Low temperature $\left(4^{\circ} \mathrm{C}\right)$ can significantly induce anthocyanin accumulation in Arabidopsis seedlings in the presence of light [24]. Intermediate temperature $\left(16^{\circ} \mathrm{C}\right)$ effectively leads to reddening in the leaves of apple and begonia [29, 30], and $15^{\circ} \mathrm{C}$ treatment promotes anthocyanin accumulation in grape peel [31]. For postharvest fruits, intermediate 


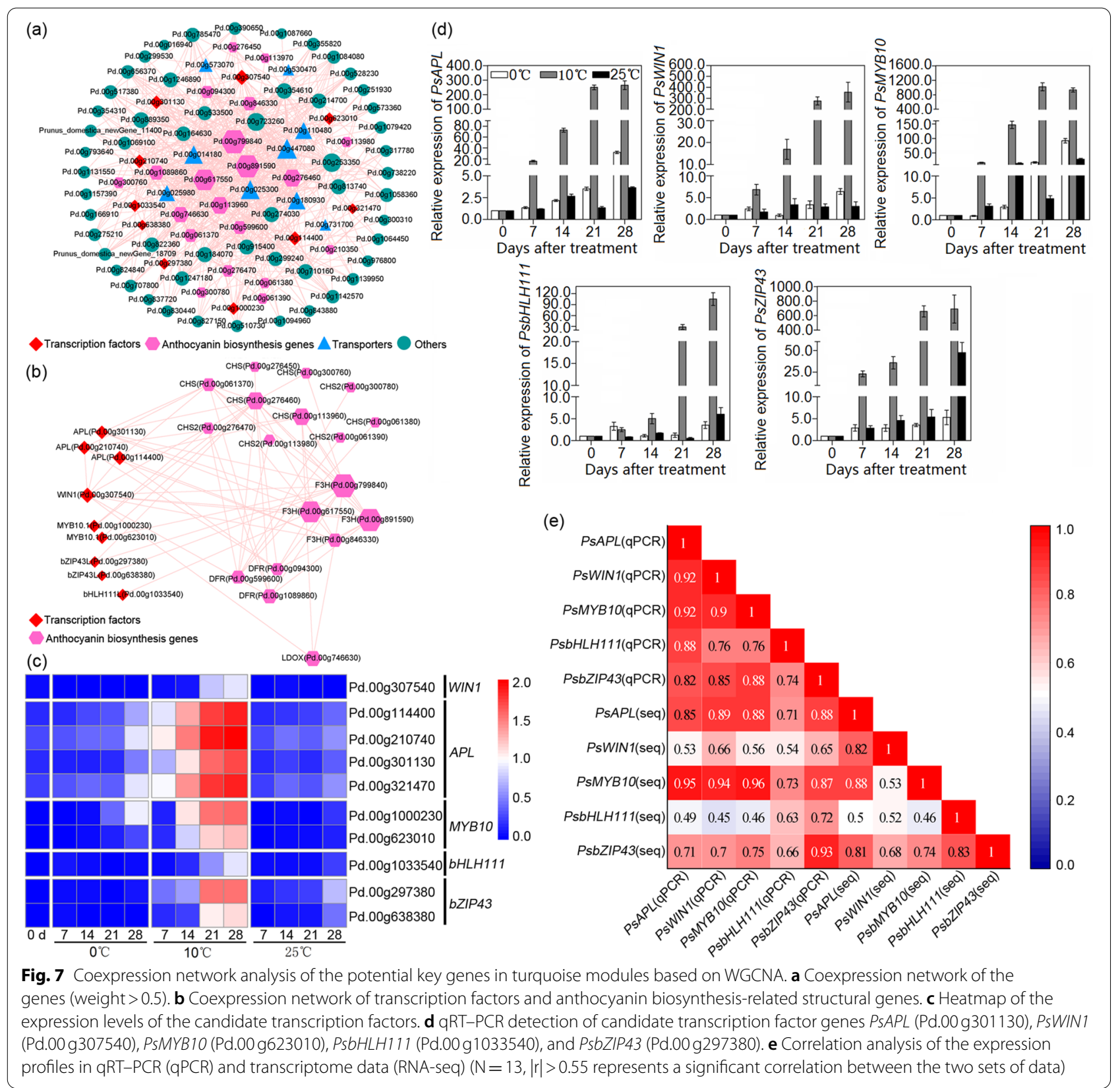

temperature also promotes the process of anthocyanin accumulation in peach, kiwifruit, sweet orange and plum fruits [26-28, 32-35]. In this work, the flesh significantly accumulated anthocyanins and appeared red on the 14th day of storage when the fruit was stored at $10^{\circ} \mathrm{C}$, while the flesh of the fruit stored at $0{ }^{\circ} \mathrm{C}$ and $25^{\circ} \mathrm{C}$ showed lower anthocyanin contents and did not redden within 28 days of storage (Fig. 1a). This was similar to the findings of a previous report [27], in which the colour of flesh rapidly changed to red once the 'Friar' plum fruit was stored at $5^{\circ} \mathrm{C}$ and $15^{\circ} \mathrm{C}$ but reddened slowly at $0^{\circ} \mathrm{C}$ or did not turn red at $25^{\circ} \mathrm{C}$. It also suggested that intermediate temperature was prone to accumulate anthocyanin in the flesh of 'Friar' plum fruit.

Anthocyanidins are widely distributed among diverse plant species. These are flavonoids that are usually present in the form of six common anthocyanidins, pelargonidin, cyanidin, delphinidin, peonidin, petunidin and malvidin. Anthocyanidins are very unstable; they can integrate with monosaccharides and disaccharides by glycosylation and then form various stable water-soluble anthocyanins [36, 37]. In this work, four anthocyanin 
components were identified in the flesh of 'Friar' plum fruit, and moreover, their contents significantly increased as the flesh reddened in plum fruit (Fig. 1 a and Fig. 2 a-d). This result was consistent with previous findings in plum fruit [27], indicating that flesh reddening under $10^{\circ} \mathrm{C}$ storage was the result of the accumulation of these four anthocyanin components. The upregulation of structural genes resulted in anthocyanin accumulation $[23,24$, $34,38]$. To understand the regulation of anthocyanin biosynthesis in 'Friar' plum fruit under intermediate temperature storage, 43 differentially expressed structural genes were found based on the transcriptome data. All of the candidate genes (PAL, 4CL, CHS, CHI, F3'H, F3H, FLS, $D F R, L D O X / A N S$ and UFGT) were completely mapped to the anthocyanin biosynthesis pathway and covered almost all of the key genes of this pathway (Fig. 5a). Moreover, the flesh of fruit stored at $10^{\circ} \mathrm{C}$ showed rapid reddening and demonstrated higher expression levels of structural genes, which were positively correlated with the accumulation of quercetin and anthocyanin (Fig. 2 and Fig. $5 \mathrm{c}$ and Fig. S3). Therefore, it was confirmed that intermediate temperature $\left(10^{\circ} \mathrm{C}\right)$ storage could promote the red colour development of flesh by increasing the transcripts of anthocyanin synthesis-related structural genes. Carbohydrates are an important substrate for anthocyanidin transformation into anthocyanins, and they have been considered a signal for regulating anthocyanin biosynthesis [39]. Galactose is the main substrate for anthocyanin synthesis in apple, and glucose can activate the activity of hexokinase (MdHXK1), which subsequently phosphorylates the MdbHLH3 transcription factor to regulate fruit reddening $[40,41]$. In grapes, carbohydrates can induce the expression of $\mathrm{F} 3 \mathrm{H}$ and then stimulate anthocyanin accumulation [42]. Among the detected carbohydrates in this study, only the sucrose content significantly increased under $10^{\circ} \mathrm{C}$ storage once the flesh appeared to redden at Day 14 (Fig. 1a and Fig. 6); in addition, the sucrose synthase (SS) genes showed higher expression levels. Thus, sucrose might be involved in anthocyanin synthesis as a substrate or signal in 'Friar' plum fruit stored at $10^{\circ} \mathrm{C}$.

\section{Transcription factors involved in anthocyanin accumulation in plum fruit}

Anthocyanin biosynthesis can be regulated by various transcription factors, and the MBW complex, which regulates anthocyanin accumulation by triggering structural genes, is well studied [43-46]. MYB10 has been proven to be involved in anthocyanin synthesis by regulating DFR, LDOX and UFGT in apple, pear, nectarine, apricot, sweet cherry, strawberry and mangosteen [22, 47-51], and PsMYB10.1 can participate in anthocyanin accumulation by regulating PsANS,
PsUFGT and PsGST in the pericarp of the postharvest 'Akihime' plum (Prunus salicina Lindl.) under $20^{\circ} \mathrm{C} /$ light treatment [32]. In addition, transient overexpression of PaMYB10 increased anthocyanin content in the peel of apricot fruit [52]. Heterologous overexpression of PpMYB10.1/PpbHLH3 and PpMYB10.3/PpbHLH3 activated anthocyanin production in tobacco leaves by upregulating $N t C H S, N t D F R$ and NtUFGT $[18,53]$. Two bHLH transcription factors, MdbHLH3 and MdbHLH33, have been confirmed to regulate DFR to promote anthocyanin biosynthesis by interacting with MYB10 in apple [54], and MdbHLH3 could regulate low temperature-induced anthocyanin synthesis by binding to the LTR (low temperature response) element of the promotor of MdMYBPA1 [55]. Moreover, bHLH3 could directly regulate the expression of structural genes to facilitate anthocyanin accumulation [23, 49]. In the present study, both transcriptome analysis and qPCR quantitative detection indicated that the expression level of MYB10 significantly increased once anthocyanin accumulated in the flesh of 'Friar' plum fruit under $10^{\circ} \mathrm{C}$ storage, and this was coordinated with the expression patterns of structural genes (Fig. 7). Thus, the transcription factor MYB10 was involved in regulating anthocyanin accumulation in 'Friar' plum fruit under intermediate temperature storage. Except for MYB10, the expression profiles of $A P L$ and $b H L H 111$ were also found to be closely related to anthocyanin accumulation and changes in the structural genes, and moreover, the expression patterns of $A P L$ and $b H L H 111$ were similar to $M Y B 10$, indicating that the transcription factors $A P L$ and $b H L H 111$ were also involved in regulating anthocyanin synthesis in 'Friar' plum fruit. The proposed function of APL is that it participates in the response to phosphorus and nitrogen deficiency and promotes flowering in Arabidopsis thaliana [56, 57]. bHLH111 has been reported to determine the competence of the pericycle for lateral root initiation in Arabidopsis thaliana [58]. However, their roles in regulating anthocyanin accumulation in postharvest fruit are unclear and need to be studied further.

The ethylene-responsive transcription factor WIN1 has been reported to be involved in wax biosynthesis and defence responses in Arabidopsis thaliana [59, 60]. In this study, $10^{\circ} \mathrm{C}$ storage induced higher expression of WIN1, which was positively correlated with anthocyanin accumulation and the expression patterns of structural genes (Fig. 7); thus, WIN1 participated in the regulation of anthocyanin biosynthesis. Previous studies have shown that MdEIL1 (EIN3-LIKE1) and MdERF1b (ETHYLENE RESPONSE FACTOR1b) promote anthocyanin synthesis by regulating transcription factors such as MdMYB1, MdMYB9 and MdMYB11 
in apple $[61,62]$. It was found that WIN1 was closely related to APL based on the analysis of the coexpression network in the present study, so it was hypothesized that WIN1 might regulate anthocyanin synthesis by interacting with APL. The transcription factor bZIP43 was found to be associated with somatic embryogenesis induction and involved in stress responses by interacting with bHLH109 in Arabidopsis [63]. Considering that anthocyanin accumulation is one of the responses to environmental stress in plants, the transcription factor bZIP43 probably plays a role in regulating anthocyanin synthesis in 'Friar' plum fruit under intermediate storage temperatures.

\section{Conclusions}

This study found that an intermediate storage temperature $\left(10^{\circ} \mathrm{C}\right)$ accelerated the process of anthocyanin accumulation in 'Friar' plum fruit. Cyanidin-3-O-glucoside and cyanidin-3-O-rutinoside contributed to the red colour of flesh. Based on the transcriptome and metabolite profile and subsequent WGCNA, 43 anthocyanin biosynthesis genes and two carbohydrate metabolismassociated genes were identified. According to the gene coexpression network constructed by WGCNA, F3H and $C H S$ were recognized as hub genes, and five transcription factors, APL, WIN1, MYB10, bZIP43 and bHLH111, were proposed to be involved in anthocyanin biosynthesis by regulating the structural genes.

\section{Methods}

\section{Materials and treatments}

'Friar' plum fruit was harvested at commercial maturity from Yi County, Baoding City, Hebei Province. The plum fruit (average single fruit weight $110 \mathrm{~g} \pm 9.25 \mathrm{~g}$; soluble solids content $10.4 \% \pm 0.96 \%$ and firmness $77.94 \mathrm{~N} \pm 6.44 \mathrm{~N}$ ) without visible defects were divided into three groups and each group (approximately 450 plums) were averagely placed in three cardboard boxes $\left(44.5 \times 31.5 \times 20.5 \mathrm{~cm}^{3}\right)$, and then stored in the dark at $25 \pm 1{ }^{\circ} \mathrm{C}\left(25^{\circ} \mathrm{C}\right), 10 \pm 0.5^{\circ} \mathrm{C}\left(10^{\circ} \mathrm{C}\right)$, and $0 \pm 0.5^{\circ} \mathrm{C}\left(0^{\circ} \mathrm{C}\right)$ with $85-90 \%$ relative humidity. The quality assays were performed at $7 \mathrm{~d}$ intervals during storage, with three repetitions of each treatment with 5 fruits per repetition, and the flesh samples were quickly frozen in liquid nitrogen and stored at $-80^{\circ} \mathrm{C}$ until use.

\section{Determination of fruit quality}

Firmness at two equidistant points on the equatorial region of fruit with skin removal was determined using a GY-4 digital fruit hardness metre (TOP Instruments Co., Hangzhou, Zhejiang, China), and firmness was calculated and expressed in Newtons (N). The soluble solids content
(SSC) was measured by a PAL-1 pocket digital refractometer (ATAGO CO., LTD., Tokyo, Japan).

\section{Determination of soluble sugar content}

Five grams of flesh powder ground in liquid nitrogen was weighed, and then $5 \mathrm{~mL}$ of $85 \%$ ethanol solution was added for ultrasonic extraction at $40^{\circ} \mathrm{C}$ for $1 \mathrm{~h}$, followed by centrifugation at $8000 \mathrm{~g}$ for $10 \mathrm{~min}$. The supernatant was collected. The extraction was repeated once more, and the supernatant was combined. After filtration through a $0.45 \mu \mathrm{m}$ PTFE microporous membrane, the combined supernatant was collected for sugar analysis by HPLC (LC-20AT, SHIMADZU CORP., Kyoto, Japan). The measurement conditions were as follows: chromatographic column: Bio-Rad Aminex HPX-87H, detector: differential RID, mobile phase: $5 \mathrm{mM}$ sulfuric acid, flow rate: $0.3 \mathrm{~mL} / \mathrm{min}$, column temperature: $40^{\circ} \mathrm{C}$, injection volume: $10 \mu \mathrm{L}$.

\section{Determination of phenolic acid and flavonoid contents Phenolic acid extraction}

Phenolic acid extracts were carried out according to Wang et al. [64] with minor modifications. Briefly, $2 \mathrm{~g}$ of freeze-dried powder was extracted with $10 \mathrm{~mL}$ of $80 \%$ methanol containing $0.5 \%$ hydrochloric acid. Afterwards, the mixture was ultrasonicated for $30 \mathrm{~min}$ and then centrifuged at $10000 \times \mathrm{g}$ at $4{ }^{\circ} \mathrm{C}$ for $10 \mathrm{~min}$. Finally, the supernatant was collected. The extraction was repeated twice, and the combined supernatants were evaporated until almost dry at $50^{\circ} \mathrm{C}$ under a gentle nitrogen stream. The resultant dry residues were redissolved in $5 \mathrm{~mL}$ of $50 \%$ $(\mathrm{v} / \mathrm{v})$ methanol/ultrapure water and filtered through a $0.22 \mu \mathrm{m}$ PTFE membrane filter (Pall, MI, USA).

\section{Flavonoid extraction}

Flavonoid extracts were performed according to the method of Gao et al. [65] with some modifications. Two grams of the freeze-dried powder of plum flesh was extracted with $30 \mathrm{~mL}$ of $80 \%$ methanol in the dark for $24 \mathrm{~h}$ at $-20^{\circ} \mathrm{C}$. Afterwards, the resultant mixture was centrifuged at $10000 \times \mathrm{g}$ at $4^{\circ} \mathrm{C}$ for $10 \mathrm{~min}$, and then the supernatant was immediately collected for analysis. The flavonoid contents were determined using UPLC-MS/ MS after filtration through $0.22 \mu \mathrm{m}$ PTFE membrane filters (Pall, MI, USA).

\section{UPLC-MS/MS analysis}

Phenolic and flavonoid analyses were performed as described previously by Gao et al. [65]. The samples were analysed by using an Acquity UPLC system (Waters, Milford, MA) with a triple quadrupole mass spectrometer (TQ-S, Waters Micromass, Manchester, UK). An acquity 
HSS C18 column $(1.8 \mu \mathrm{m}$ particle size; $2.1 \times 150 \mathrm{~mm}$; Waters, Milford, MA, USA) was used to perform chromatographic separation. The column and sample managers were maintained at $40^{\circ} \mathrm{C}$ and $10^{\circ} \mathrm{C}$, respectively. The mobile phase used for the separation consisted of (A) $0.1 \%$ $(\mathrm{v} / \mathrm{v})$ formic acid in water and (B) $0.1 \%(\mathrm{v} / \mathrm{v})$ formic acid in acetonitrile. Samples were eluted according to a linear gradient: $0.5-4.5 \mathrm{~min}, 5-30 \% \mathrm{~B} ; 4.5-9.0 \mathrm{~min}, 30-90 \%$; 9.0-10.0 $\mathrm{min}, 0.5 \% \mathrm{~B}$, and a flow rate of $0.3 \mathrm{~mL} \mathrm{~min}^{-1}$.

The mass spectrometer was operated in both positive and negative ionization modes, depending on the structure and properties of the compounds. The parameters were as follows: capillary voltage, $+2.5 \mathrm{kV} /-1.0 \mathrm{kV}$; source temperature, $150^{\circ} \mathrm{C}$; desolvation temperature, $500^{\circ} \mathrm{C}$; cone gas flow, $150 \mathrm{~L} \mathrm{~h}^{-1}$; and desolvation gas flow, $1000 \mathrm{Lh}^{-1}$. Detection was carried out in multiple reaction monitoring (MRM) mode. All analyte-dependent parameters were conducted according to our previously published study [65]. MassLynxTM 4.1 software (Waters) was used for data acquisition and processing. Quantitative determinations were performed using the standard curves generated from individual compounds in serial dilutions (1-500 $\left.\mathrm{ng} \mathrm{m}^{-1}\right)$.

\section{Transcriptome sequencing and WGCNA}

Total RNA was extracted from 'Friar' flesh samples stored at $0{ }^{\circ} \mathrm{C}, 10^{\circ} \mathrm{C}$ and $25^{\circ} \mathrm{C}$ for 7 days, 14 days, 21 days and 28 days (three biological repetitions), and RNA concentration and purity were measured using a NanoDrop 2000 (Thermo Fisher Scientific, Wilmington, DE). RNA integrity was assessed using the RNA Nano 6000 Assay Kit of the Agilent Bioanalyzer 2100 system (Agilent Technologies, CA, USA). A total amount of $1 \mu \mathrm{g}$ of RNA per sample was used as input material for the RNA sample preparations. Sequencing libraries were generated using the NEBNext UltraTM RNA Library Prep Kit for Illumina (NEB, USA) following the manufacturer's recommendations, and index codes were added to attribute sequences to each sample. Library quality was assessed with the 2100 Bioanalyzer system. After the library inspection was qualified, different libraries were pooled according to the target data volume and sequenced by the Illumina platform. The off-board data were filtered to obtain clean data, compared with the reference genome of European plum [66] to obtain mapped data, and evaluated for library quality, such as insert length tests and randomness tests. Then, structural-level analysis, such as alternative splicing analysis, new gene discovery and gene structure optimization, was carried out. The expression levels of differentially expressed genes, functional annotation and functional enrichment of differentially expressed genes were analysed. Finally, the transcriptome data and phenotypic data were analysed by WGCNA using $R$ language.

\section{RNA extraction and qPCR analysis}

Total RNA from flesh was extracted by the CTAB method [67]. RNA $(0.8 \mu \mathrm{g}$, OD260:OD280 between 1.80 and 2.0, OD260:OD230>1.5, no obvious degradation by electrophoresis) was used for reverse transcription by PrimeScript ${ }^{\mathrm{TM}}$ RT Reagent Kit with gDNA Eraser (Takara Biomedicals, Dalian, China). The products were diluted 15 times with nuclease-free water and then subjected to real-time fluorescence quantitative PCR (qPCR) with a TB Green ${ }^{\circledR}$ Premix Ex Taq $^{\text {TM }}$ II (Tli RNaseH Plus) kit (TaKaRa Biomedicals).

Quantitative real-time (qRT)-PCR assays were conducted using an Applied Biosystems 7500 Fast Real-Time PCR System. The reaction system was $20 \mu \mathrm{L}$, including $10 \mu \mathrm{L}$ of $2 \mathrm{X}$ Green Premix Ex Taq II (Tli RNaseH Plus), $0.8 \mu \mathrm{L}$ each of gene specific upstream primer and downstream primer, $0.4 \mu \mathrm{L}$ of ROX Reference Dye II (50X), $2 \mu \mathrm{L}$ of diluted cDNA, and $6 \mu \mathrm{L}$ of nuclease-free water. The running program was set as follows: $30 \mathrm{~s}$ at $95^{\circ} \mathrm{C}$ for one cycle, $5 \mathrm{~s}$ at $95^{\circ} \mathrm{C}$ and $34 \mathrm{~s}$ at $60^{\circ} \mathrm{C}$ for 40 cycles. PsACTIN7 was used as the internal reference. The primers used in this paper are listed in Additional file 1: Table S1. The relative expression levels of genes were calculated according to the $2^{-\triangle \triangle \mathrm{Ct}}$ method.

\section{Statistical analysis}

Each experiment was performed in three replicates. Experimental results were analysed using GraphPad Prism 8, Origin 2021, IBM SPSS Statistics 23, RStudio, and Cytoscape 3.7.1 software. Error bars denote standard deviations. Different lowercase letters above the bars indicate significant differences $(P<0.05)$, which were obtained based on one-way ANOVA by LSD and DUNCAN tests using IBM SPSS Statistics 23 software.

\section{Abbreviations}

WGCNA: Weighted gene co-expression correlation network analysis; ROS: Reactive oxygen species; EBGs: Early biosynthesis genes; LBGs: Late biosynthesis genes; PAL: Phenylalnine ammonialyase; CHS: Chalcone synthase; $\mathrm{CHI}$ : Chalcone isomerase; F3H: Flavanone 3-hydroxylase; F3'H: Flavonoid-3'hydroxylase; DFR: Dihydroflavonol 4-reductase; LDOX/ANS: Leucoanthocyanidin dioxygenase/Anthocyanin synthetase; UFGT: UDP-glucose: flavonoid 3-O-glucosyltransferase; MBW: MYB-bHLH-WD40; COP1: CONSTITUTIVE PHOTOMORPHOGENIC 1; JAZ: JASMONATE ZIM-DOMAIN; NAC: NAM, ATAF1/2, CUC2; SPL: SQUAMOSA promoter-binding protein-like; HXK: Hexokinase; SS: sucrose synthases; APL: MYB family transcription factor APL; MYB10: MYB10 transcription factor; WIN1: Ethylene-responsive transcription factor WIN1; bZIP43: Basic leucine zipper 43-like; bHLH111: Transcription factor bHLH111like isoform X2; LTR: Low temperature response; MdEIL1: EIN3-LIKE1; MdERF1b: ETHYLENE RESPONSE FACTOR1 b; DAT: Days after treatment; SSC: Soluble solids content; FPKM: Fragments per kilobase of exon model per million mapped fragments; DEGs: Differentially expressed genes; UPLC-MS/MS: ultraperformance liquid chromatography-tandem mass spectrometry; HPLC: High performance liquid chromatography. 


\section{Supplementary Information}

The online version contains supplementary material available at https://doi. org/10.1186/s12870-021-03354-2.

Additional file 1: Figure S1. GO enrichment of the genes in turquoise module. Figure S2. KEGG enrichment of the genes in turquoise module. Figure S3. Correlation analysis of expression profiles of anthocyanin biosynthesis related genes, anthocyanin components and quercetin content. Table S1. The primers used in this study.

\section{Acknowledgements}

We would like to acknowledge all the teachers and students from the laboratory of the College of Life Science of Hebei Normal University and the Agriculture Institute of Biotechnology and Food Science of Hebei Academy of Agriculture and Forestry Sciences for their help.

\section{Authors' contributions}

J.F.G and Y.D.C conceived the project and designed the experiments. X.L.L performed the experiment and write the manuscript. M.W performed the phenolic acid and flavonoid detection. S.J.C, J.F.G and Y.D.C guided the operation of the experiment and assisted with writing. The author(s) read and approved the final manuscript.

\section{Funding}

This work was supported by the HAAFS Agriculture Science and Technology Innovation Project (2019-2-1), the National Natural Science Foundation of China (315018012) and the Young Talents Fund of Hebei province.

\section{Availability of data and materials}

The datasets supporting the conclusions of this article are included within the article (and its additional file(s).

\section{Declarations}

Ethics approval and consent to participate

Not applicable.

\section{Consent for publication}

Not applicable.

\section{Competing interests}

The authors declare that they have no competing interests.

\section{Author details}

${ }^{1}$ College of Life Science, Hebei Normal University, Shijiazhuang, Hebei Province 050024, People's Republic of China. ${ }^{2}$ Institute of Biotechnology and Food Science, Hebei Academy of Agriculture and Forestry Sciences, Shijiazhuang, Hebei Province 050051, People's Republic of China. ${ }^{3}$ Plant Genetic Engineering Center of Hebei Province, Shijiazhuang, Hebei Province 050051, People's Republic of China. ${ }^{4}$ Beijing Research Center for Agricultural Standards and Testing, Beijing Academy of Agricultural and Forestry Sciences, Beijing, People's Republic of China.

Received: 21 September 2021 Accepted: 17 November 2021 Published online: 06 December 2021

\section{References}

1. Bai S, Tao R, Yin L, Ni J, Yang Q, Yan X, et al. Two B-box proteins, PpBBX18 and $\mathrm{PpBBX} 21$, antagonistically regulate anthocyanin biosynthesis via competitive association with Pyrus pyrifolia ELONGATED HYPOCOTYL 5 in the peel of pear fruit. Plant J. 2019;100:1208-23.

2. Davies KM, Albert NW, Schwinn KE. From landing lights to mimicry: the molecular regulation of flower colouration and mechanisms for pigmentation patterning. Funct Plant Biol. 2012;39:619-38.
3. Lev-Yadun S, Gould KS. Role of anthocyanins in plant defence. In: Winefield C, Davies K, Gould K, editors. Anthocyanins. New York: Springer; 2008. p. 22-8.

4. Tsuda T. Dietary anthocyanin-rich plants: biochemical basis and recent progress in health benefits studies. Mol Nutr Food Res. 2012;56:159-70.

5. Pelletier MK, Murrell JR, Shirley BW. Characterization of flavonol synthase and leucoanthocyanidin dioxygenase genes in Arabidopsis. Further evidence for differential regulation of "early" and "late" genes. Plant Physiol. 1997:113:1437-45.

6. Jeong SW, Das PK, Jeoung SC, Song JY, Lee HK, Kim YK, et al. Ethylene suppression of sugar-induced anthocyanin pigmentation in Arabidopsis. Plant Physiol. 2010;154:1514-31.

7. Ni J, Zhao Y, Tao R, Yin L, Gao L, Strid A, et al. Ethylene mediates the branching of the jasmonate-induced flavonoid biosynthesis pathway by suppressing anthocyanin biosynthesis in red Chinese pear fruits. Plant Biotechnol J. 2020;18:1223-40.

8. Saito K, Yonekura-Sakakibara K, Nakabayashi R, Higashi Y, Yamazaki M, Tohge T, et al. The flavonoid biosynthetic pathway in Arabidopsis: structural and genetic diversity. Plant Physiol Biochem. 2013;72:21-34.

9. Gonzalez A, Zhao M, Leavitt JM, Lloyd AM. Regulation of the anthocyanin biosynthetic pathway by the TTG1/bHLH/Myb transcriptional complex in Arabidopsis seedlings. Plant J. 2008;53:814-27.

10. Xu W, Dubos C, Lepiniec L. Transcriptional control of flavonoid biosynthesis by MYB-bHLH-WDR complexes. Trends Plant Sci. 2015;20:176-85.

11. Zimmermann IM, Heim MA, Weisshaar B, Uhrig JF. Comprehensive identification of Arabidopsis thaliana MYB transcription factors interacting with R/B-like BHLH proteins. Plant J. 2004:40:22-34.

12. Koes R, Verweij W, Quattrocchio F. Flavonoids: a colorful model for the regulation and evolution of biochemical pathways. Trends Plant Sci. 2005;10:236-42.

13. Gonzalez A, Brown M, Hatlestad G, Akhavan N, Smith T, Hembd A, et al. TTG2 controls the developmental regulation of seed coat tannins in Arabidopsis by regulating vacuolar transport steps in the proanthocyanidin pathway. Dev Biol. 2016;419:54-63.

14. Gou JY, Felippes FF, Liu CJ, Weigel D, Wang JW. Negative regulation of anthocyanin biosynthesis in Arabidopsis by a miR156-targeted SPL transcription factor. Plant Cell. 2011;23:1512-22.

15. Maier A, Schrader A, Kokkelink L, Falke C, Welter B, Iniesto E, et al. Light and the E3 ubiquitin ligase COP1/SPA control the protein stability of the MYB transcription factors PAP1 and PAP2 involved in anthocyanin accumulation in Arabidopsis. Plant J. 2013;74:638-51.

16. Qi T, Song S, Ren Q, Wu D, Huang H, Chen Y, et al. The Jasmonate-ZIMdomain proteins interact with the WD-repeat/bHLH/MYB complexes to regulate Jasmonate-mediated anthocyanin accumulation and trichome initiation in Arabidopsis thaliana. Plant Cell. 2011;23:1795-814.

17. Verweij W, Spelt CE, Bliek M, de Vries M, Wit N, Faraco M, et al. Functionally similar WRKY proteins regulate vacuolar acidification in petunia and hair development in Arabidopsis. Plant Cell. 2016;28:786-803.

18. Zhou H, Lin-Wang K, Wang H, Gu C, Dare AP, Espley RV, et al. Molecular genetics of blood-fleshed peach reveals activation of anthocyanin biosynthesis by NAC transcription factors. Plant J. 2015;82:105-21.

19. Bai S, Saito T, Moriguchi T, Honda C, Hatsuyama Y, Ito A. An apple B-box protein, MdCOL11, is involved in UV-B- and temperature-induced anthocyanin biosynthesis. Planta. 2014;240:1051-62.

20. Crifo T, Puglisi I, Petrone G, Recupero GR, Lo Piero AR. Expression analysis in response to low temperature stress in blood oranges: implication of the flavonoid biosynthetic pathway. Gene. 2011;476:1-9.

21. Das PK, Shin DH, Choi SB, Park YI. Sugar-hormone cross-talk in anthocyanin biosynthesis. Mol Cell. 2012;34:501-7.

22. Feng $S$, Wang $Y$, Yang $S, X u Y$, , Chen $X$. Anthocyanin biosynthesis in pears is regulated by a R2R3-MYB transcription factor PyMYB10. Planta. 2010:232:245-55.

23. Xie XB, Li S, Zhang RF, Zhao J, Chen YC, Zhao Q, et al. The bHLH transcription factor MdbHLH3 promotes anthocyanin accumulation and fruit colouration in response to low temperature in apples. Plant Cell Environ. 2012:35:1884-97.

24. Zhang Y, Liu Z, Liu R, Hao H, Bi Y. Gibberellins negatively regulate low temperature-induced anthocyanin accumulation in a $\mathrm{HY} 5 / \mathrm{HYH}$-dependent manner. Plant Signal Behav. 2011;6:632-4. 
25. Zhang C, Jia H, Wu W, Wang X, Fang J, Wang C. Functional conservation analysis and expression modes of grape anthocyanin synthesis genes responsive to low temperature stress. Gene. 2015;574:168-77.

26. Zhu YC, Zhang B, Allan AC, Lin-Wang K, Zhao Y, Wang K, et al. DNA demethylation is involved in the regulation of temperature-dependent anthocyanin accumulation in peach. Plant J. 2020;102:965-76.

27. Wang R, Wang L, Yuan S, Li Q, Pan H, Cao J, et al. Compositional modifications of bioactive compounds and changes in the edible quality and antioxidant activity of 'Friar' plum fruit during flesh reddening at intermediate temperatures. Food Chem. 2018;254:26-35.

28. Wang L, Sang W, Xu R, Cao J. Alteration of flesh color and enhancement of bioactive substances via the stimulation of anthocyanin biosynthesis in 'Friar' plum fruit by low temperature and the removal. Food Chem. 2020;310:125862.

29. Song T, Li K, Wu T, Wang Y, Zhang X, Xu X, et al. Identification of new regulators through transcriptome analysis that regulate anthocyanin biosynthesis in apple leaves at low temperatures. PLoS One. 2019;14:e0210672.

30. Tian J, Han ZY, Zhang LR, Song TT, Zhang J, Li JY, et al. Induction of anthocyanin accumulation in crabapple (Malus CV.) leaves by low temperatures. HortScience. 2015;50:640-9.

31. Azuma A, Yakushiji H, Koshita Y, Kobayashi S. Flavonoid biosynthesisrelated genes in grape skin are differentially regulated by temperature and light conditions. Planta. 2012;236:1067-80.

32. Fang Z, Lin-Wang $K$, Jiang C, Zhou D, Lin Y, Pan S, et al. Postharvest temperature and light treatments induce anthocyanin accumulation in peel of'Akihime' plum (Prunus salicina Lindl.) via transcription factor PsMYB10.1. Postharvest Biol Technol. 2021:179:1-11.

33. Li B, Xia Y, Wang Y, Qin G, Tian S. Characterization of genes encoding key enzymes involved in anthocyanin metabolism of kiwifruit during storage period. Front Plant Sci. 2017;8:1-8.

34. Sicilia A, Scialo E, Puglisi I, Lo Piero AR. Anthocyanin biosynthesis and DNA methylation dynamics in sweet orange fruit [Citrus sinensis L. (Osbeck)] under cold stress. J Agric Food Chem. 2020;68:7024-31.

35. Yu M, Man Y, Wang Y. Light- and temperature-induced expression of an R2R3-MYB gene regulates anthocyanin biosynthesis in red-fleshed kiwifruit. Int J Mol Sci. 2019;20:1-22.

36. Tanaka Y, Sasaki N, Ohmiya A. Biosynthesis of plant pigments: anthocyanins, betalains and carotenoids. Plant J. 2008:54:733-49.

37. Alappat B, Alappat J. Anthocyanin pigments: beyond aesthetics. Molecules. 2020;25:1-17.

38. Ban Y, Honda C, Hatsuyama Y, Igarashi M, Bessho H, Moriguchi T, et al. Isolation and functional analysis of a MYB transcription factor gene that is a key regulator for the development of red coloration in apple skin. Plant Cell Physiol. 2007:48:958-70.

39. Finkelstein RR, Gibson SI. ABA and sugar interactions regulating development: cross-talk or voices in a crowd? Curr Opin Plant Biol. 2002:5:26-32

40. Ban Y, Kondo S, Ubi BE, Honda C, Bessho H, Moriguchi T. UDP-sugar biosynthetic pathway: contribution to cyanidin 3-galactoside biosynthesis in apple skin. Planta. 2009;230:871-81.

41. Hu DG, Sun CH, Zhang QY, An JP, You CX, Hao YJ. Glucose sensor MdHXK1 phosphorylates and stabilizes MdbHLH3 to promote anthocyanin biosynthesis in apple. PLoS Genet. 2016;12:1-27.

42. Zheng Y, Tian L, Liu H, Pan Q, Zhan J, Huang W. Sugars induce anthocyanin accumulation and flavanone 3-hydroxylase expression in grape berries. Plant Growth Regul. 2009;58:251-60.

43. Baudry A, Heim MA, Dubreucq B, Caboche M, Weisshaar B, Lepiniec L. TT2, TT8, and TTG1 synergistically specify the expression of BANYULS and proanthocyanidin biosynthesis in Arabidopsis thaliana. Plant $\mathrm{J}$. 2004:39:366-80.

44. Petroni K, Tonelli C. Recent advances on the regulation of anthocyanin synthesis in reproductive organs. Plant Sci. 2011;181:219-29.

45. Naing AH, Kim CK. Roles of R2R3-MYB transcription factors in transcriptional regulation of anthocyanin biosynthesis in horticultural plants. Plant Mol Biol. 2018:98:1-18.

46. He Q, Ren Y, Zhao W, Li R, Zhang L. Low temperature promotes anthocyanin biosynthesis and related gene expression in the seedlings of purple head chinese cabbage (Brassica rapa L.). Genes (Basel). 2020;11:1-23.

47. Palapol Y, Ketsa S, Lin-Wang K, Ferguson IB, Allan AC. A MYB transcription factor regulates anthocyanin biosynthesis in mangosteen (Garcinia mangostana L.) fruit during ripening. Planta. 2009;229:1323-34.
48. Lin-Wang K, Bolitho K, Grafton K, Kortstee A, Karunairetnam S, McGhie TK, et al. An R2R3 MYB transcription factor associated with regulation of the anthocyanin biosynthetic pathway in Rosaceae. BMC Plant Biol. 2010;10:1-17.

49. Ravaglia D, Espley RV, Henry-Kirk RA, Andreotti C, Ziosi V, Hellens RP, et al. Transcriptional regulation of flavonoid biosynthesis in nectarine (Prunus persica) by a set of R2R3 MYB transcription factors. BMC Plant Biol. 2013;13:1-14

50. Medina-Puche L, Cumplido-Laso G, Amil-Ruiz F, Hoffmann T, Ring L, Rodriguez-Franco A, et al. MYB10 plays a major role in the regulation of flavonoid/phenylpropanoid metabolism during ripening of Fragariax ananassa fruits. J Exp Bot. 2014;65:401-17.

51. Starkevic P, Paukstyte J, Kazanaviciute V, Denkovskiene E, Stanys V Bendokas $V$, et al. Expression and anthocyanin biosynthesis-modulating potential of sweet cherry (Prunus avium L.) MYB10 and bHLH genes. PLoS One. 2015;10:e0126991

52. Xi W, Feng J, Liu Y, Zhang S, Zhao G. The R2R3-MYB transcription factor PaMYB10 is involved in anthocyanin biosynthesis in apricots and determines red blushed skin. BMC Plant Biol. 2019;19:287.

53. Rahim MA, Busatto N, Trainotti L. Regulation of anthocyanin biosynthesis in peach fruits. Planta. 2014;240:913-29.

54. Espley RV, Hellens RP, Putterill J, Stevenson DE, Kutty-Amma S, Allan AC. Red colouration in apple fruit is due to the activity of the MYB transcription factor, MdMYB10. Plant J. 2007:49:414-27.

55. Wang N, Qu C, Jiang S, Chen Z, Xu H, Fang H, et al. The proanthocyanidinspecific transcription factor MdMYBPA1 initiates anthocyanin synthesis under low-temperature conditions in red-fleshed apples. Plant J. 2018:96:39-55.

56. Todd CD, Zeng P, Huete AM, Hoyos ME, Polacco JC. Transcripts of MYB-like genes respond to phosphorous and nitrogen deprivation in Arabidopsis. Planta. 2004;219:1003-9.

57. Abe M, Kaya H, Watanabe-Taneda A, Shibuta M, Yamaguchi A, Sakamoto $T$, et al. FE, a phloem-specific Myb-related protein, promotes flowering through transcriptional activation of FLOWERING LOCUS T and FLOWERING LOCUS T INTERACTING PROTEIN 1. Plant J. 2015;83:1059-68.

58. Zhang Y, Mitsuda N, Yoshizumi T, Horii Y, Oshima Y, Ohme-Takagi M, et al. Two types of bHLH transcription factor determine the competence of the pericycle for lateral root initiation. Nat Plants. 2021;7:633-43.

59. Aharoni A, Dixit S, Jetter R, Thoenes E, van Arkel G, Pereira A. The SHINE clade of AP2 domain transcription factors activates wax biosynthesis, alters cuticle properties, and confers drought tolerance when overexpressed in Arabidopsis. Plant Cell. 2004;16:2463-80.

60. Broun $\mathrm{P}$, Poindexter $\mathrm{P}$, Osborne $\mathrm{E}$, Jiang $\mathrm{CZ}$, Riechmann JL. WIN1, a transcriptional activator of epidermal wax accumulation in Arabidopsis. PNAS. 2004;101:4706-11.

61. An JP, Wang XF, Li YY, Song LQ, Zhao LL, You CX, et al. EIN3-LIKE1, MYB1, and ETHYLENE RESPONSE FACTOR3 act in a regulatory loop that synergistically modulates ethylene biosynthesis and anthocyanin accumulation. Plant Physiol. 2018;178:808-23.

62. Zhang J, Xu H, Wang N, Jiang S, Fang H, Zhang Z, et al. The ethylene response factor MdERF1B regulates anthocyanin and proanthocyanidin biosynthesis in apple. Plant Mol Biol. 2018;98:205-18.

63. Nowak K, Gaj MD. Stress-related function of bHLH109 in somatic embryo induction in Arabidopsis. J Plant Physiol. 2016:193:119-26.

64. Wang M, Jiang $N$, Wang $Y$, Jiang $D$, Feng $X$. Characterization of phenolic compounds from early and late ripening sweet cherries and their antioxidant and antifungal activities. J Agric Food Chem. 2017;65:5413-20.

65. Gao $Y$, Wang M, Jiang N, Wang $Y$, Feng $X$. Use of ultra-performance liquid chromatography-tandem mass spectrometry on sweet cherries to determine phenolic compounds in peel and flesh. J Sci Food Agric. 2019:99:3555-62.

66. Zhebentyayeva T, Shankar V, Scorza R, Callahan A, Ravelonandro M, Castro $\mathrm{S}$, et al. Genetic characterization of worldwide Prunus domestica (plum) germplasm using sequence-based genotyping. Hortic Res. 2019;6:1-13.

67. Gasic K, Hernandez A, Korban SS. RNA extraction from different apple tissues rich in polyphenols and polysaccharides for CDNA library construction. Plant Mol Biol Report. 2004;22:437-8.

\section{Publisher's Note}

Springer Nature remains neutral with regard to jurisdictional claims in published maps and institutional affiliations. 